\title{
Separation of 1-Butanol by Pervaporation Using Polymer Inclusion Membranes Containing Ionic Liquids
}

\author{
Michiaki MATSUMOTO,* Yuuki MURAKAMI and Kazuo KONDO \\ Department of Chemical Engineering and Materials Science \\ Doshisha University, Kyotanabe, Kyoto 610-0321 Japan \\ (Received December 30, 2010; Accepted February 15, 2011)
}

\begin{abstract}
Pervaporation of 1-butanol and isopropyl alcohol (IPA) through a poly vinyl chloride membrane (PVC) as the active layer and a porous hydrophobic polyvinyldene fluoride membrane as the support layer was conducted by dissolving ionic liquids, such as Aliquat 336, Cyphos 101, 102 and 104 in PVC. The effects of the ionic liquids, membrane thickness and feed concentration on the permeation flux, selectivity and separation factor at room temperature were examined and it was found that the membrane with the ratio of Aliquat $336 / \mathrm{PVC}=70 / 30(\mathrm{w} / \mathrm{w})$ gave the highest permeability and separation factor.
\end{abstract}

\section{Introduction}

1-Butanol has been widely used as a raw material for various chemicals and as a solvent in the chemical industry. Furthermore, 1-butanol is of current interest as a fuel for the internal combustion engine. In particular biobutanol, which was produced by microbes such as Clostridium beyerinckii from biomass, has been of interest as a biofuel [1]. However, because many by-products such as isopropanol (IPA), acetone, and ethanol are produced in the fermentation broth, development of an effective separation method of 1-butanol from the broth is required. Separation of 1-butanol using conventional distillation is energy-intensive, since the normal boiling point of 1-butanol is higher than water. Although some separation methods like gas stripping [2], adsorption [3], solvent extraction [4], combination of distillation and pervaporation [5] have been proposed, recently the separation method that produces 1-butanol directly from the fermentation liquids by pervaporation is preferred because of its high selectivity and low energy requirement.

Because 1-butanol is more hydrophobic than coexisting isopropanol, ethanol and water in the broth, hydrophobic membrane materials such as polylsiloxane [6], polyether block amide [7], polyvinilidene fluoride [8] and polyldimethylsiloxane (PDMS) [9] have been used to preferentially permeate 1-butanol. Among those membranes, PDMS gives a good performance and a promising potential because of its highly hydrophobic properties and good thermal, chemical and mechanical stability [10]. The addition of silicalite to the PDMS membrane was examined to enhance the 
permeability and separation factor of 1-butanol [11,12]. Moreover, Izák et al. examined supported liquid membranes based on a mixed solution of PDMS and an ionic liquid (tetrapropylammonium tetracyanoborate) for separation of acetone and 1-butanol to enhance the permeability and separation factor [13]. However, the supported liquid membranes have a critical problem in that they lack long-term stability, that is, leaking of the impregnated ionic liquids from the support membrane due to the large pressure difference in the pervaporation process.

Therefore, in this study, in order to improve membrane stability we selected a polymer inclusion membrane (PIM) that is obtained by casting a solution containing an ionic liquid and a base polymer, poly(vinyl chloride) (PVC) to form a thin, flexible and stable film. PIMs have been applied to the separation of metals and small organic compounds and have given outstanding performances compared to other types of liquid membranes particularly in terms of membrane lifetime [14]. Ionic liquids, which are known as green solvents in separation processes, have been extensively studied because they basically have negligible vapor pressure, which makes them replacements for volatile organic solvents. We examined the separation of 1-butanol and IPA by pervaporation using a polymer inclusion membrane containing ionic liquids.

\section{Experimental}

\subsection{Membrane preparation}

Hydrophobic porous polyvinyldene fluoride (PVDF) membranes (Millipore, average micropore diameter $0.22 \mu \mathrm{m}$, membrane thickness $125 \mu \mathrm{m}$ ) were used as the support membrane. In preliminary experiments, hydrophilic PVDF and nylon membranes failed to support the PIM and the permeabilities through poly(tetrafluoroetylene) were much lower than that for hydrophobic PVDF. Hydrophobic PVDF was selected as the support membrane for these reasons. Cyphos IL-101, 102, 104, and 109, Aliquat 336 and $[\mathrm{Bmim}]\left[\mathrm{PF}_{6}\right]$ were used as the ionic liquids in this study and their molecular structures are shown in Table 1.

The PIM was prepared by the solution casting method. Polymer solution was prepared by dissolving PVC and the ionic liquid in tetrahydrofuran (THF). The solution mixture was stirred with a homogenizer, and poured into a petri-dish. After evaporating the THF for $24 \mathrm{~h}$ at room temperature, the resultant PIM was obtained with an average film thickness of $220-250 \mu \mathrm{m}$. The PIM so prepared was placed on the support membrane, hydrophobic PVDF.

\subsection{Pervaporation experiment}

A schematic diagram of the apparatus for the pervaporation experiments is shown in Fig. 1. A double membrane consisting of the PIM and hydrophobic PVDF was placed in the membrane holder. A ternary mixture (water/IPA/1-butanol) was circulated over the double membrane in the membrane holder by a peristaltic pump providing a flow of $10 \mathrm{ml} / \mathrm{min}$. Vacuum was provided on the downstream side of the membrane using a vacuum pump. The permeate was collected in a cold trap immersed in liquid nitrogen.

The permeate flux was determined gravimetrically from the weight of the permeate sample collected over a given period of time. The concentrations of 1-butanol and IPA in the permeate were 
determined by HPLC (Shimadzu LC-10ADvp) with a refractive index detector (Shimadzu RID-10A). Analysis was performed using a Shodex SUGAR SH-1011 (Showa Denko) column and a $5 \mathrm{mM}$ $\mathrm{H}_{2} \mathrm{SO}_{4}$ solution as the mobile phase. Based on the pervaporation experimental data, the membrane performance can be characterized in terms of the total permeation flux $(J)$, the selectivity $(S)$ between 1-butanol and IPA, the separation coefficient $(\alpha)$ between water and 1-butanol as shown below:

Table 1 Ionic liquids used in this study

\begin{tabular}{|c|c|}
\hline \multirow{2}{*}{$\begin{array}{c}\mathrm{C}_{8} \mathrm{H}_{17} \mathrm{H}_{17} \\
\mathrm{C}_{8} \mathrm{H}_{17} \\
\end{array}$} & Aliquat 336 \\
\hline & Trioctylmethylammonium chloride \\
\hline \multirow{2}{*}{$\mathrm{C}_{6} \mathrm{H}_{13} \mathrm{P}_{1}^{+}-\mathrm{C}_{14} \mathrm{H}_{29}$} & Cyphos IL 101 \\
\hline & Trihexyltetradecylphosphonium chloride \\
\hline \multirow{2}{*}{$\begin{array}{l}\mathrm{C}_{6} \mathrm{H}_{13} \mathrm{P}^{+} \\
\mathrm{C}_{6} \mathrm{H}_{13} / \mathrm{P}_{1}^{+}-\mathrm{C}_{14} \mathrm{H}_{29} \\
\mathrm{C}_{6} \mathrm{H}_{13}\end{array}$} & Cyphos IL 102 \\
\hline & Trihexyltetradecylphosphonium bromide \\
\hline \multirow{2}{*}{$\begin{array}{cc}\mathrm{C}_{6} \mathrm{H}_{13} \\
\mathrm{C}_{6} \mathrm{P}_{13}^{+}-\mathrm{C}_{14} \mathrm{H}_{29} \\
\mathrm{C}_{6} \mathrm{H}_{13} & \mathrm{O}_{1}^{\prime} \mathrm{O}_{-} \mathrm{C}_{8} \mathrm{H}_{17} \\
\mathrm{C}_{8} \mathrm{H}_{17} \\
\end{array}$} & Cyphos IL 104 \\
\hline & $\begin{array}{l}\text { Trihexyltetradecylphosphonium } \\
\text { bis-2,4,4-trimethylpentylphosphinate }\end{array}$ \\
\hline \multirow{2}{*}{ 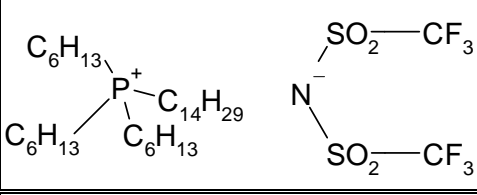 } & Cyphos IL 109 \\
\hline & $\begin{array}{l}\text { Trihexyltetradecylphosphonium bis-trifluoromethylsulfonyl } \\
\text { imide }\end{array}$ \\
\hline \multirow{2}{*}{$\left\langle\prod_{\mathrm{N}^{N}}^{\mathrm{N}^{+}-\mathrm{C}_{4} \mathrm{H}_{9}} \mathrm{PF}_{6}\right.$} & {$[\mathrm{Bmim}]\left[\mathrm{PF}_{6}\right]$} \\
\hline & 1-Butyl-3-methylimidazolium hexafluorophosphate \\
\hline
\end{tabular}

Total permeation flux

$$
J=\frac{Q}{A t}
$$

Selectivity

$$
S=\frac{J_{\mathrm{Bt}}}{J_{\mathrm{IPA}}}
$$

Separation factor

$$
\alpha=\frac{w_{P, B t} / w_{P, W}}{w_{F, B t} / w_{F, W}}
$$

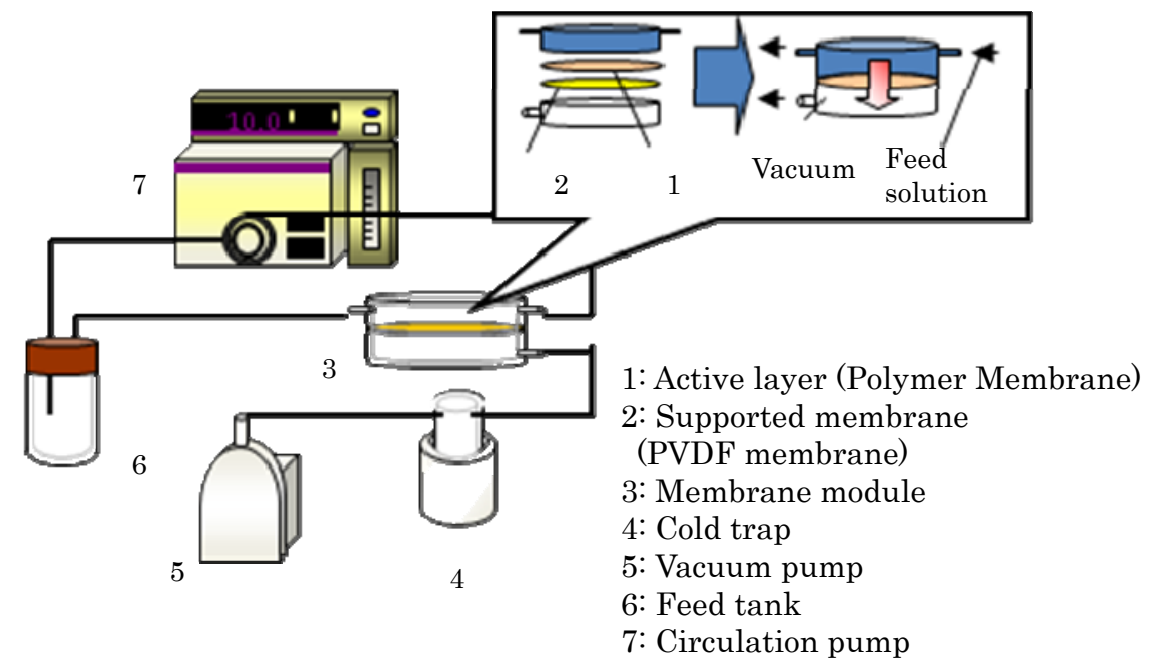

Figure 1. Schematic diagram of the pervaporation apparatus 
where $Q$ is the mass of permeate collected over a time interval $t, A$ is the effective membrane area for permeation, and $w_{P}$ and $w_{F}$ are mass fractions in the permeate and feed, respectively. Subscripts $\mathrm{Bt}$, IPA and $\mathrm{W}$ denote 1-butanol, isopropanol and water, respectively. The partial permeation fluxes of 1-butanol $\left(J_{\mathrm{Bt}}\right)$ and IPA $\left(J_{\mathrm{IPA}}\right)$ can be easily obtained from the total flux and the permeate composition.

\section{Results and Discussion}

\subsection{Effect of ionic liquid on permeability}

First the effect of ionic liquid on the permeability was examined. Figure 2 shows the fluxes, selectivity and separation factors under different mass ratios of ionic liquid to PVC. Figure 2 (a) and (b), and (c) and (d) show the results for ionic liquid (IL)/PVC ratios of 60/40 and 70/30 wt/wt. In the case of the IL/PVC ratio of 50/50, the total flux gave extremely high values and the separation factor became almost unity because macropores in the PIM were formed, suggesting that this PIM cannot play the role of a functional membrane. Similar phenomena were observed whenever $[\mathrm{Bmim}]\left[\mathrm{PF}_{6}\right]$ and Cyphos IL 109 were used. In the cases of the IL/PVC ratios of 60/40 and 70/30 using Cyphos IL-101, 102, 104, and Aliquat 336 as the ionic liquids, pervaporation experiments were successfully operated and the membranes were stable without leaking ionic liquids during the operating time. When the mass fraction of the ionic liquid exceeded $70 \%$, the film strength was insufficient for pervaporation. From Figure 2 (a) and (c), it can be seen that the permeation fluxes of 1-butanol were higher than those of IPA and the separation factor is greater than unity, because 1-butanol is more hydrophobic than IPA and water. Furthermore, the permeation fluxes at an IL/PVC ratio of $70 / 30$ are generally higher than those for IL/PVC ratio of 60/40, suggesting that the amount of 1-butanol and IPA extracted increases with increasing amounts of ionic liquid in the PIM. On the other hand, in both cases, the selectivity and the separation factor are relatively insensitive to the amount of ionic liquid. This suggests that 1-butanol and IPA permeate mainly through the ionic liquid domain. Hereafter, the membrane with an IL/PVC ratio of 70/30 using Aliquat 336 was selected, because it had the highest flux and a relatively high separation factor.

\subsection{Effect of feed solution concentration on permeability}

The influence of the 1-butanol and IPA feed concentrations on the membrane performance at room temperature was examined using the Aliquat $336 / \mathrm{PVC}=70 / 30$ membrane with a $220-250 \mu \mathrm{m}$ thickness. Figure 3 shows the effect of feed concentration in the range of $2.0-10.0 \mathrm{~g} / \mathrm{L}$ on the permeation characteristics. 1-Butanol and IPA fluxes increased approximately linearly with increasing 1-butanol and IPA concentrations in the feed solution. This is due to the increase in the amount of extracted 1-butanol and IPA with increasing feed concentration. On the other hand, the separation factor and selectivity decreased slightly. This may be due to a change in the polarity in the membrane phase caused by the distribution of alcohol to the membrane phase. However, because the extent of the decrease in the separation factor and selectivity were relatively small, given the 1-butanol concentration in the fermentation broth, it can be said that separation factor and selectivity were insensitive to the feed concentration. 

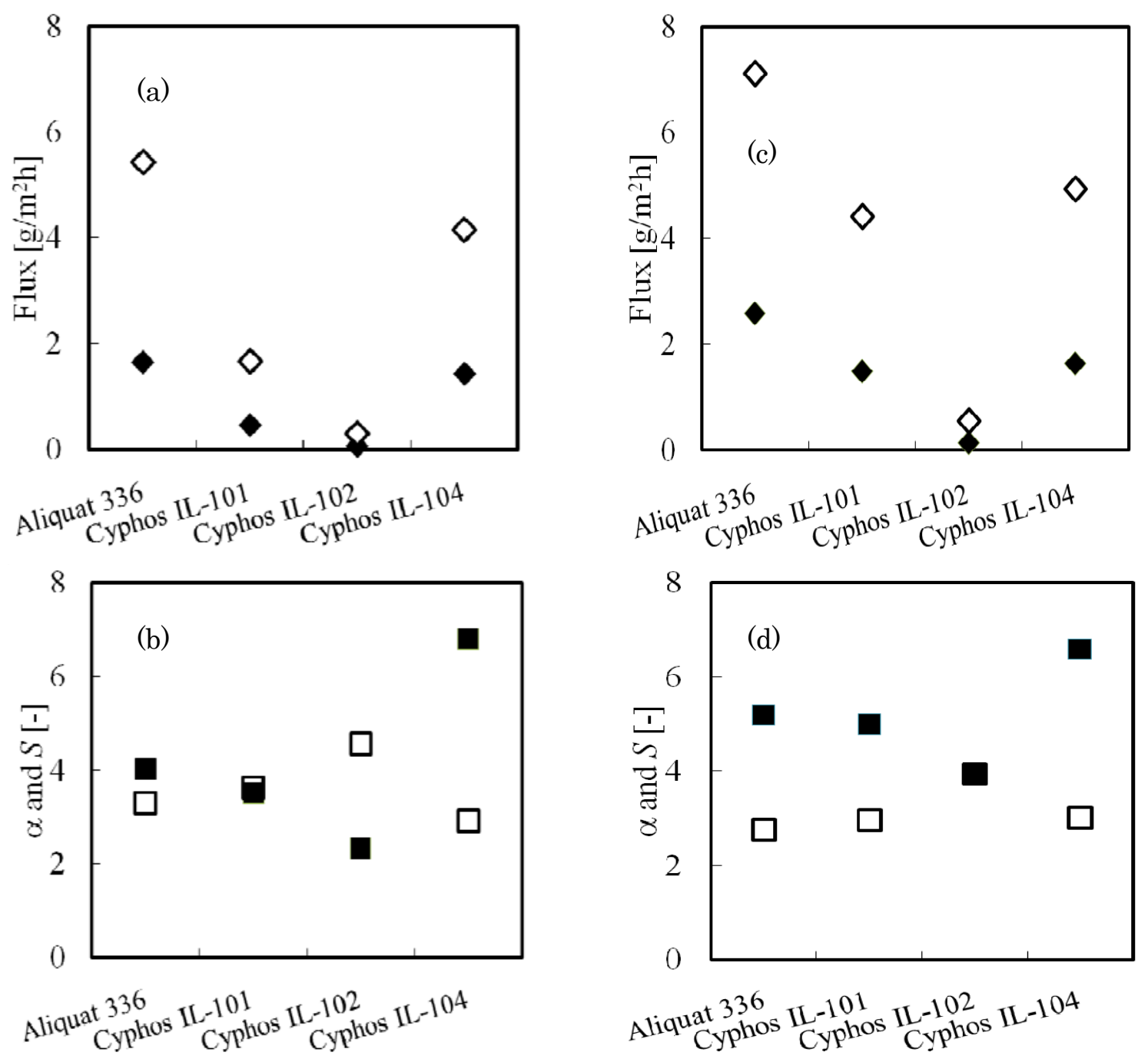

Figure 2. Effect of the ionic liquid on the pervaporation characteristics. Feed IPA and 1-butanol concentrations were $5 \mathrm{~g} / \mathrm{l}$. (a) and (b) $\mathrm{IL} / \mathrm{PVC}=60 / 40$, (c) and (d) $\mathrm{IL} / \mathrm{PVC}=70 / 30$, and the average membrane thickness $230 \mu \mathrm{m}, \diamond: 1$-Butanol flux,
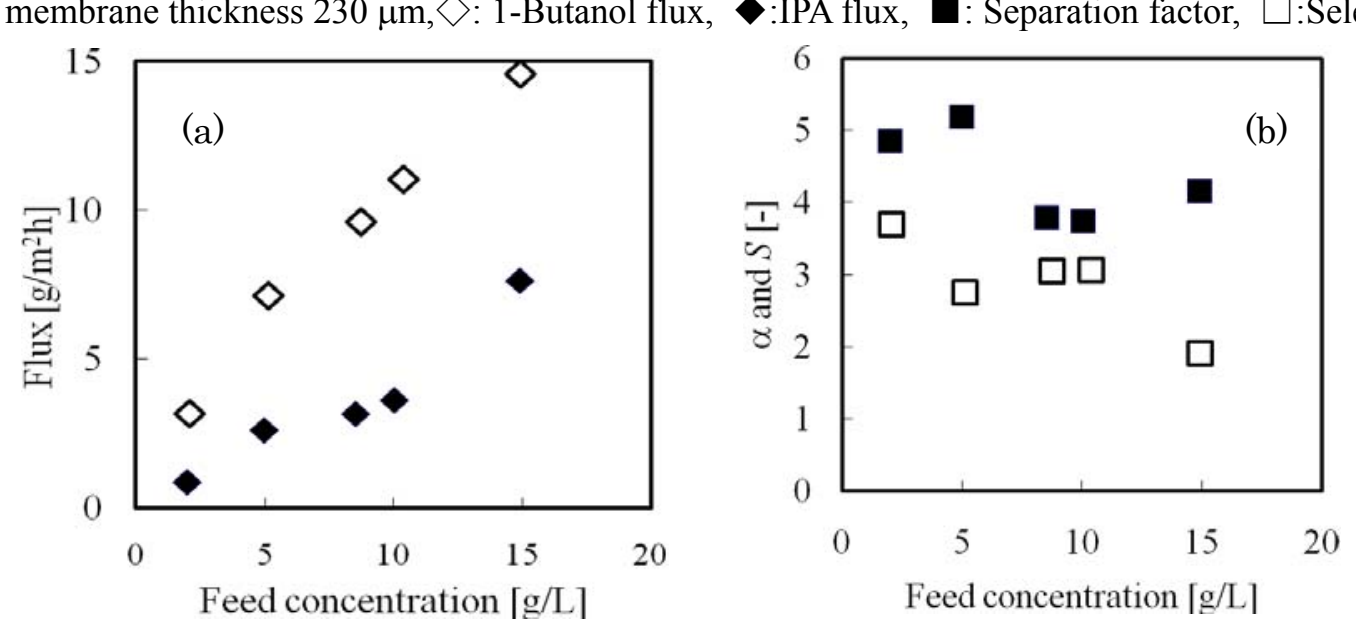

Figure 3. Effect of feed concentration on the pervaporation characteristics with the Aliquat 336/PVC=70/30 membrane. (a): IPA and 1-butanol flux, (b): separation factor and selectivity. $\diamond$ : 1-Butanol flux, $\diamond$ :IPA flux, $\mathbf{\square}$ : Separation factor, $\square$ :Selectivity. 


\subsection{Effect of membrane thickness on permeability}

Next, the influence of membrane thickness for pervaporation performance on the permeability was examined to determine the contribution of the membrane resistance to the permeation flux. The thickness of the PIM could be changed in the range of 31-339 $\mu \mathrm{m}$ by adjusting the amount of mixture including PVC, THF and ionic liquid added to the petri dish. In this paper, membrane thickness means the thickness of the PIM as the active layer. Figure 4 shows the effect of membrane thickness on the pervaporation permeation characteristics. 1-Butanol and IPA fluxes decreased with increasing membrane thickness, while the separation factor was relatively insensitive to the membrane thickness except for the thicker membranes and the selectivity slightly increased. In this study, the highest 1-butanol flux, $26.08 \mathrm{~g} / \mathrm{m}^{2} \mathrm{~h}$, was obtained for the $31 \mu \mathrm{m}$ thick PIM.
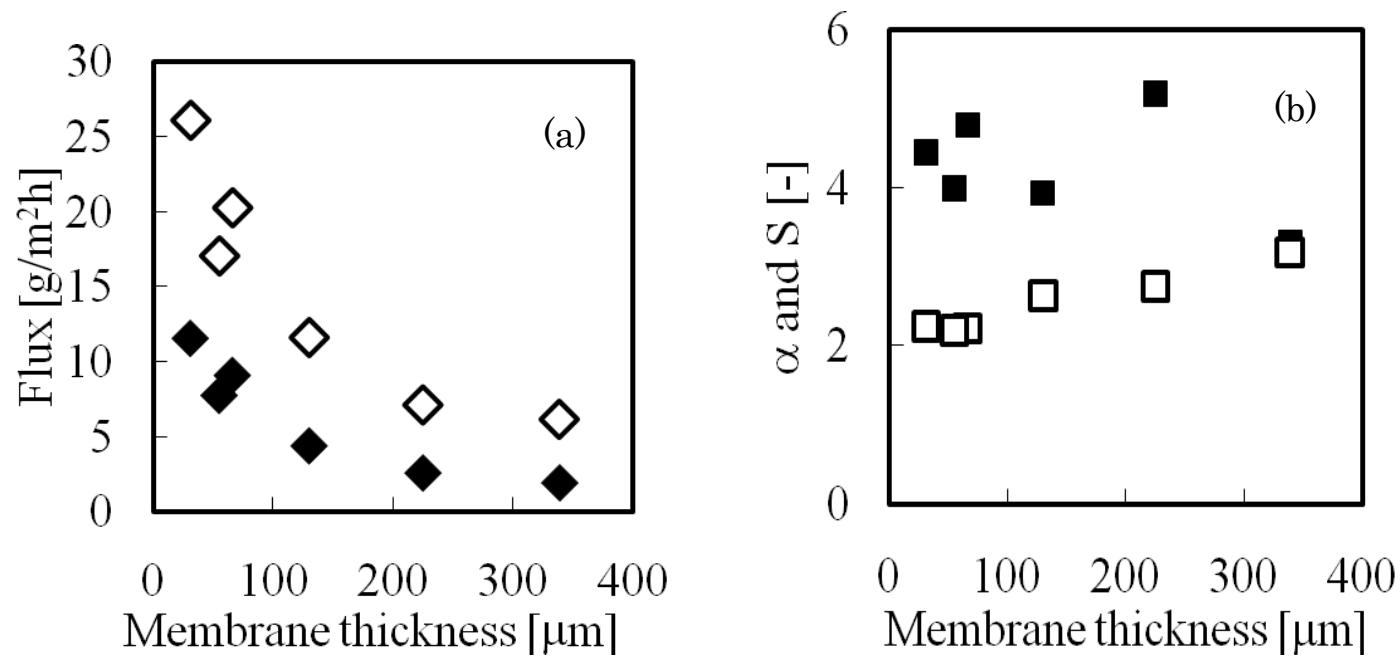

Figure 4. Effect of membrane thickness on the pervaporation characteristics with the Aliquat 336/PVC $=70 / 30$ membrane. Feed IPA and 1-butanol concentrations were 5 g/l. (a) IPA and 1-butanol flux, (b) separation factor and selectivity $\diamond$ : 1-Butanol flux, $\diamond$ :IPA flux, $\mathbf{\square}$ : Separation factor, $\square$ :Selectivity.

Generally, the flux $\left(J_{\mathrm{Bt}}\right)$ through a membrane is expressed by the following equation:

$$
J_{B t}=K_{o v}\left(C_{b, f}-C_{b, p}\right)
$$

where $K_{o v}$ is the overall mass transfer coefficient through the membrane. $C_{b, f}$ and $C_{b, p}$ are the feed and permeate concentrations of 1-butanol, respectively. Because the permeate side is under vacuum conditions, $C_{b, p}$ is negligible and Eq.(4) is simplified to Eq. (5)

$$
J_{B t}=K_{o v} C_{b, f}
$$

The overall resistance to mass transfer $1 / K_{o v}$ is considered to be the sum of the membrane resistance $1 / K_{m}$ and the boundary layer resistance $1 / K_{L}$.

$$
\frac{1}{K_{o v}}=\frac{1}{K_{L}}+\frac{1}{K_{m}}=\frac{1}{K_{L}}+\frac{\delta}{P}
$$


where $K_{m}$ and $K_{L}$ are the mass transfer coefficients in the membrane and in the liquid boundary layer, respectively, $P$ is permeation coefficient and $\delta$ is the membrane thickness. The $K_{o v}$ value was easily obtained from the pervaporation experiment using Eq. (5). Figure 5 shows the relation between the overall resistance and membrane thickness. The boundary layer resistance $1 / K_{L}$ can be determined from the intercept of the plot and is found to be $154 \mathrm{~h} / \mathrm{m}$. The contributions of membrane resistance and boundary layer resistance to the overall resistance were calculated and listed in Table 2.

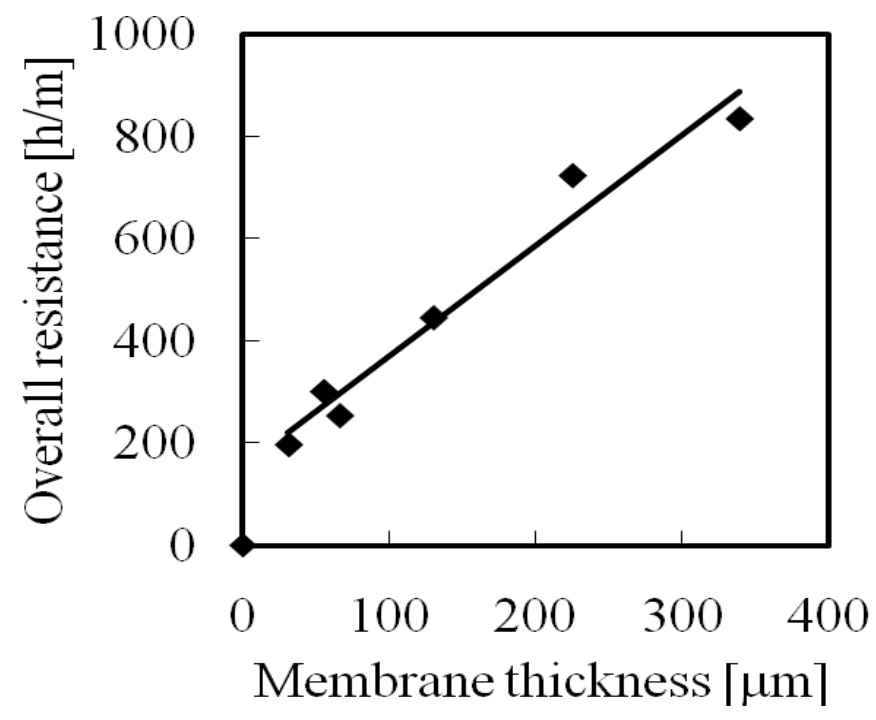

Figure 5. Relationship between overall resistance and membrane thickness.

Table 2 Contribution of membrane resistance and boundary layer resistance to the overall resistance

\begin{tabular}{cccc}
\hline $\begin{array}{c}\text { Membrane } \\
\text { thickness }[\mu \mathrm{m}]\end{array}$ & $\begin{array}{c}\text { Overall resistance } \\
{[\mathrm{h} / \mathrm{m}]}\end{array}$ & $\begin{array}{c}\text { Percentage of membrane } \\
\text { resistance [\%] }\end{array}$ & $\begin{array}{c}\text { Percentage of boundary } \\
\text { layer resistance [\%] }\end{array}$ \\
\hline 31 & 196 & 21.69 & 78.31 \\
55 & 300 & 48.74 & 51.26 \\
66 & 253 & 39.20 & 60.80 \\
130 & 445 & 65.37 & 34.63 \\
225 & 723 & 78.69 & 21.31 \\
339 & 834 & 81.53 & 18.47 \\
\hline
\end{tabular}

Fouad and Feng reported that the percentage of the membrane resistance $\left(1 / K_{m}\right)$ to the overall resistance $\left(1 / K_{o v}\right)$ is $85-97 \%$ for a dense polyether-polyamide block-copolymer (PEBA) membrane [7]. Because the thickness of the PIM is controlled by adjusting the experimental conditions, a membrane with low membrane resistance can be easily prepared compared with other membranes. Table 3 summarizes the results, along with those of previous studies for 1-butanol pervaporation. The 1-butanol flux obtained in this study is comparable to the other results, while the separation factor is 
somewhat smaller. However, when the apparatus with a smaller film resistance will be used, the PIM may give the larger permeability. Further work is required to find a more 1-butanol selective ionic liquid against water.

\section{Conclusion}

Pervaporation of 1-butanol and IPA through polymer inclusion membranes containing ionic liquids was successfully carried out by using Aliquat 336, Cyphos IL 101, 102 and 104. The separation of 1-butanol and IPA was controlled by the solubility difference in the ionic liquid. Aliquat 336 is found to be the most suitable ionic liquid for the pervaporation separation of 1-butanol and IPA. The 1-butanol and IPA fluxes increased with decreasing membrane thickness, and with increasing feed concentration, while the separation factor and selectivity were insensitive to these parameters. The highest 1-butanol flux obtained in this study was $26.08 \mathrm{~g} / \mathrm{m}^{2} \mathrm{~h}$ with a $31 \mu \mathrm{m}$ thick PIM, which was comparable to the results with other membranes.

Table 3 Membrane performance for 1-butanol pervaporation

\begin{tabular}{llllllll}
\hline Membrane & Feed & $\begin{array}{l}\text { Temp. } \\
{\left[{ }^{\circ} \mathrm{C}\right]}\end{array}$ & $\begin{array}{l}\text { Membrane } \\
\text { thickness }[\mu \mathrm{m}]\end{array}$ & $\begin{array}{l}J_{\text {total }} \\
{\left[\mathrm{g} / \mathrm{m}^{2} \mathrm{~h}\right]}\end{array}$ & $\begin{array}{l}J_{\mathrm{Bt}} \\
{\left[\mathrm{g} / \mathrm{m}^{2} \mathrm{~h}\right]}\end{array}$ & $\alpha$ & Ref. \\
\hline GFT-PDMS & $1 \mathrm{wt} \%$ & 40 & 190 & 900 & 30.0 & 26.8 & 11 \\
Sillicalite-PDMS & $10 \mathrm{~g} / \mathrm{L}$ & 40 & 19 & & $30 \sim 45$ & 110 & 12 \\
PDMS & $5 \sim 10 \mathrm{~g} / \mathrm{L}$ & 37 & 65 & $80 \sim 100$ & $8 \sim 22$ & $26 \sim 34$ & 10 \\
SILM-PDMS & $6 \mathrm{~g} / \mathrm{L}$ & 23 & & & $8 \sim 22$ & & 13 \\
PEBA 2533 & $0.3 \mathrm{wt} \%$ & 29 & 30 & $\sim 100$ & 4 & 12 & 7 \\
PIM & $5 \mathrm{~g} / \mathrm{L}$ & 25 & 225 & 280 & 7.1 & 5.2 & This work \\
PIM & $5 \mathrm{~g} / \mathrm{L}$ & 25 & 31 & 1193 & 26 & 4.5 & This work \\
\hline
\end{tabular}

\section{Acknowledgment}

This work was supported by "Creating Research Center for Advanced Molecular Biochemistry", Strategic Development of Research Infrastructure for Private Universities, the Ministry of Education, Culture, Sports, Science and Technology, Japan.

\section{References}

1) T. Jojima, M. Inui and H. Yukawa, Appl. Microbiol. Biotechnol. 77, 1219-1224 (2008)

2) N. Qureshi, B.C. Saha, R.E. Hector, S.R. Hughes and M.A. Cotta, Biomass Bioenergy, 32, 168-175 (2008)

3) A. Oudshoorn, L.A.M. van der Wielen, A.J.J. Straathof, Biochem. Eng. J., 48, 99-103 (2009)

4) S.H. Ha, N. L. Mai and Y.M. Koo, Process Biochem., in press

5) X. Qiao, T.S. Chunga, W.F. Guo, T. Matsuura, M.M. Teoh, J. Membr. Sci., 252, 37-49 (2005)

6) V. García, E. Pongrácz, E. Muurinen, R.L. Keiski, Desalination, 241, 201-211 (2009)

7) E.A. Fouad and X. Feng, J. Membr. Sci., 323, 428-435 (2008) 
8) K. Srinivasan, K. Palanivelu, A.N. Gopalakrishnan, Chem. Eng. Sci., 62, 2905-2914 (2007)

9) Y. Wang, S.H. Goh, T.S. Chung and P. Na, J. Membr. Sci., 326, 222-233 (2009)

10) S.Y. Li, R. Srivastava and R.S. Parnas, J. Membr. Sci., 363, 287-294 (2010)

11) A. Jonquires and A. Fane, J. Membr. Sci., 125, 245-255 (1997)

12) J. Huang and M.M. Meagher, J. Membr. Sci., 192, 231-242 (2001)

13) P. Izák, K. Schwarz, W. Ruth, H. Bahl and U. Kragl, Appl. Microbiol. Biotechnol. 78, 597-602 (2008)

14) L.G. Nighim, P. Mornane, I.D. Potter, J.M. Perera, R.W. Cattrall and S.D. Kolev, J. Membr. Sci., 281, 7-41 (2006) 